\title{
The Department of Pathology at the German Primate Center from 1973 to 1999
}

\author{
M. Brack ${ }^{1, *}$ \\ ${ }^{1}$ German Primate Center (DPZ), Göttingen, Germany \\ * retired
}

Correspondence to: M. Brack (brackconsultant@t-online.de)

Received: 2 June 2015 - Revised: 6 August 2015 - Accepted: 6 August 2015 - Published: 23 September 2015

\begin{abstract}
The Department of Pathology was the first scientific unit established at the German Primate Center (DPZ) already in its planning phase. At that early time the planning of administrative duties was also necessary, including the financial framework of the laboratory equipment of the then-envisioned three departments of pathology, virology and physiology, in order to get the DPZ off the ground. Otherwise the functions of the Department of Pathology were both service duties and scientific evaluations. The service functions after the establishment of the DPZ included pathological, bacteriological and parasitological examinations/surveys and the veterinary care of nonhuman primates at the DPZ and other primate colonies. On an international level its service functions were reflected by the collaboration within the Office International de Epizooties (OIE, Paris) (Dollinger et al., 1996) and the Infectious Diseases Working Group of the European Association of Zoo and Wildlife Veterinarians, and the establishment of a bacteriological laboratory in Iquitos, Peru, at the request of the Pan American Health Organization.

Parallel to those administrative and service duties to the DPZ and to international communities, the different scientific activities started, which in a pathology department always are a combination of service and research. They are documented by a total of almost 120 publications, including 3 doctoral theses and 116 publications by the author from 1973 to 1999; the most important ones are summarized in the following examples.
\end{abstract}

\section{Apes}

\subsection{Perinatal telencephalic leukoencephalopathy in chimpanzees}

This white-matter disorder observed in 16 captive born chimpanzees of different origins, ranging in age from 3.5 months to 21 years, is morphologically similar to periventricular leukomalacia of man. Globular acid glycosaminoglycans and sparse proteins accumulated particularly in, but not restricted to, the Virchow-Robin spaces in the prosencephalon, the thalamus adjacent to the internal capsule, the lentiform nucleus and rarely the caudal nucleus (Brack, 1973).

\subsection{Suspected Dermatophilus congolensis infection in a female orangutan of the Vienna Zoo}

A 16-year-old hand-raised female Bornean orangutan came down with a vesicular dermatosis of the entire trunk and all extremities, followed by severe pruritus, alopecia, depression, general weakness and totally suppressed sexual cycles. Euthanasia for humane reasons was considered because the condition seemed untreatable after the diagnosis of an infected eczema by a local laboratory and failure of all treatments. In a last step to avoid the loss of that genetically valuable animal (the Bornean variety of the orangutan is under extreme pressure of extinction), a skin biopsy was forwarded to the DPZ. At histopathology the characteristic signs of a cutaneous Dermatophilus congolensis (Actinomycetales, Dermatophilaceae) infection were clearly present; spiramycin treatment was suggested and subsequently employed. Three weeks later the orangutan resumed playing with its care- 


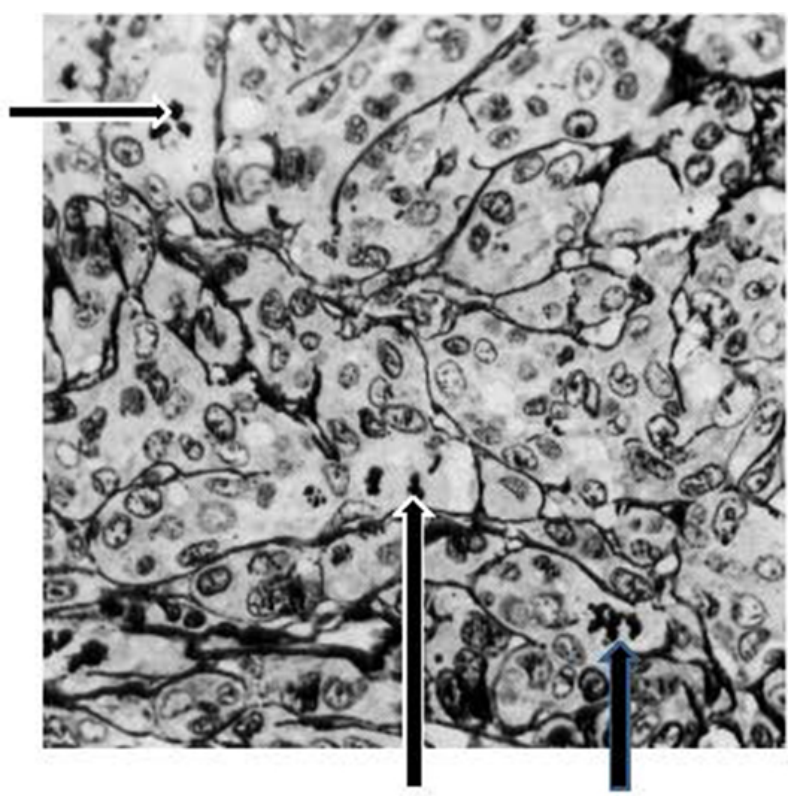

Figure 1. Tupaia belangeri: sebaceous jugulo-sternal gland carcinoma; Movat, $100 \times$. Arrows: atypical mitotic figures.

taker, the pruritus had stopped, and the hair started to regrow; 2 months later the animal experienced its first menstruation in 2 years (Brack et al., 1997b). Although morphologically clearly diagnosed and successfully treated, the infection could not be verified by cultivation of the actinomycetes, because sterile sampling would have required another use of general anesthesia in the weakened animal.

\section{Old World primates}

\subsection{Experimental SA8 infections in newborn baboons (Papio cynocephalus)}

Herpesvius SA8 belongs to the epitheliotropic Alphaherpesvirinae, a group also including herpesviruses hominis types 1 and 2 and B virus (Cercopithecine herpesvirus 1). All alphaherpesviruses have a tendency to infect also the brain, especially in foreign hosts. SA8 normally causes urogenital infections in adult baboons, and has possibly caused fatal pneumonias in numerous newborn baboons at the Southwest Foundation for Research and Education, San Antonio, Texas, USA.

The question was whether they represented intrauterine (diaplacental) or postnatal infections. Therefore both routes were experimentally simulated by intravenous versus intratracheal infections of neonatal, 6-month-old and 1-yearold baboons. The results were that intravenous inoculation of SA8 caused only minor, transient pulmonary interstitial responses, whereas intratracheal infections induced fatal necrotizing pneumonias as observed in the spontaneous cases.

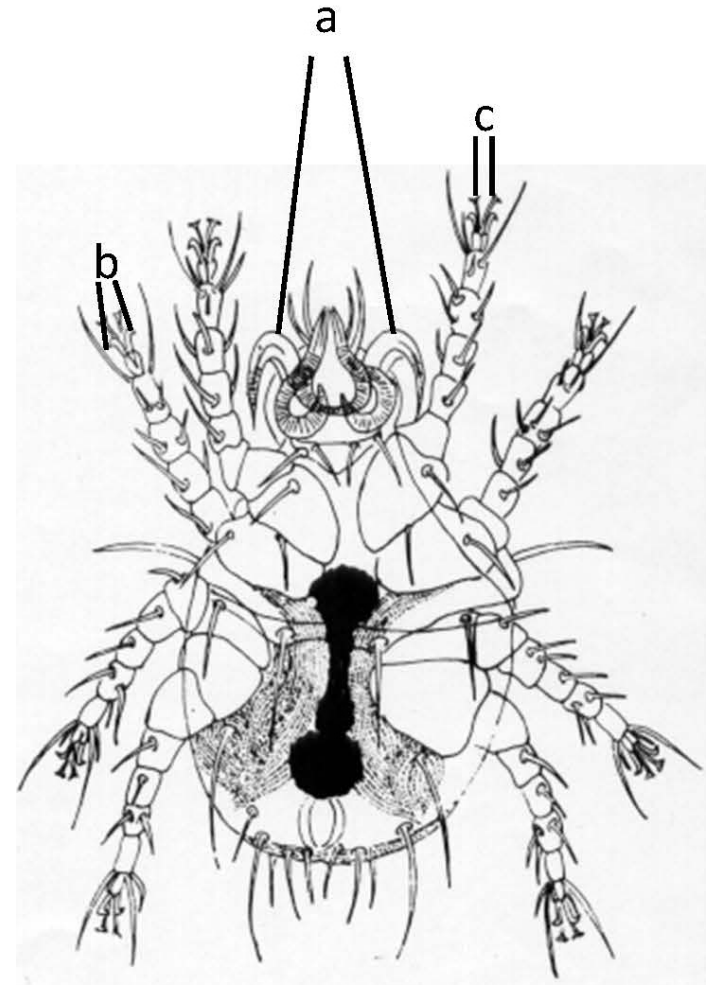

Figure 2. Criokeron quintus - female, $100 \times$. (a) Gnathostomal hooks, (b) tarsal hooks, (c) tarsal attachment organs.

Additional examinations concentrated on the central nervous system of the experimentally infected animals. Intravenous infections caused minor diffuse meningoencephalitis in all parts of the brains; intratracheal infections, in contrast, induced inclusion body encephalitis limited to the vagal root, such as the medullary bundles of the $\mathrm{N}$. vagus within the medulla oblongata, the substantia reticularis myelencephali, vagal dorsal nucleus, nucleus of the solitary tract, and in two animals within the spinal tract of the trigeminal nerve. The caudal limits were the decussation of the lateral corticospinal tract; the anterior borders were the basal parts of the di- and telencephalon. The lesions never reached the cortex (Brack et al., 1981a, b); altogether the results pointed to postnatal infections as the natural route. The outbreak was finally stopped by acyclovir treatment.

\subsection{Bilateral posterior parietal atrophy in a juvenile rhesus monkey appearing as subtotal blindness (Brack and Gatesman, 1989)}

A naturally born and raised rhesus monkey infant developed behavioral abnormalities and visual impairment. At 1.5 years of age it was decided to euthanize the animal for humane reasons. At necropsy and histopathology both cerebral parietal lobes were atrophic, with the sunken areas reaching anteriorly from the central sulci to the lunate sulci at the posterior 


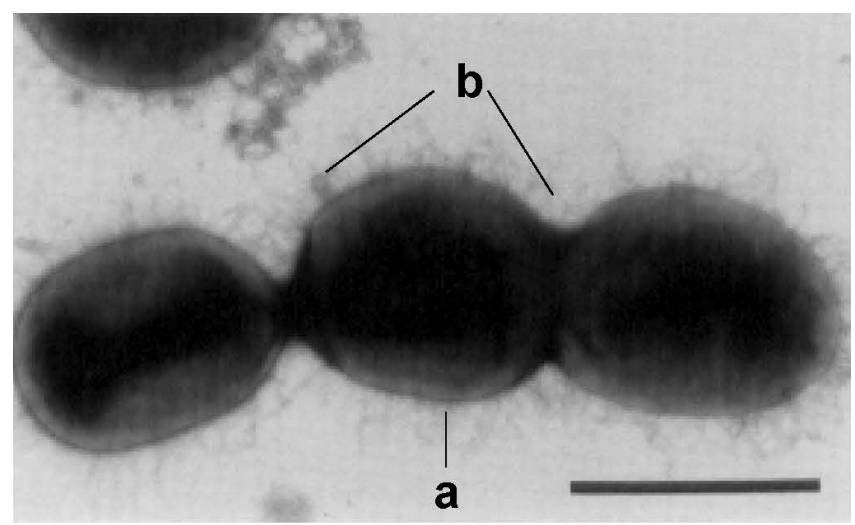

Figure 3. Brackiella oedipodis - bar $=100 \mu \mathrm{m}$. (a) Bacterial cell wall, (b) abundant fimbriae.

end, medially to the angulate gyrus and ventrolaterally going halfway down the temporal lobes, thus encompassing the brain areas 5 and 7, and parts of areas 18 and 22. The optic chiasm, however, was unaffected. The causes of that peculiar disease remained unknown, but the report of several cases of "neonatal blindness" in the colony of origin at Cayo Santiago makes a viral etiology possible, since the Cayo Santiago colony is latently infected with Cercopithecine herpesvirus 1 (B virus).

\subsection{Alveolar echinococcosis in rhesus monkeys at the DPZ}

Echinococcus multilocularis (fox tapeworm), which is endemic in southern Germany and the adjacent parts of France and Switzerland, infected several macaques at the DPZ. The first case occurred in 1993 in a 12-year-old female rhesus monkey, initially misdiagnosed as pregnancy because of the greatly distended abdomen. When closer examination could not confirm the pregnancy, the animal was sacrificed. Necropsy revealed numerous cysts of different sizes, particularly in liver and lung, which at histopathology were found to be protoscolices, with some in the lung apparently still viable. EM2plus-ELISA tests confirmed the suspected identity as E. multilocularis (Brack et al., 1997d).

This interesting case exemplifies the rapid expansion of the fox tapeworm. For example, E.multilocularis never appeared in the former German Democratic Republic before the political fall of the wall but is now present in Thuringia, Brandenburg, etc.; the first infected foxes in the Göttingen area were reported in 1990.

The route of infection of the monkeys at the DPZ can only be speculated. Because physical contact with foxes or fox feces was virtually impossible in the reported case, the most likely way was through contaminated branches or foliage taken from the nearby forest for environmental enrichment of the enclosures.

\subsection{Streptococcus equi ssp., zooepidemicus in lion-tailed macaques (Macaca silenus) at the Rheine Zoo (Brack et al., 1997a)}

Three out of 10 wanderoos (lion-tailed macaques) at the Rheine Zoo, Rheine, Germany, died within 2 days peracutely or were found dead; the last one, a young-adult female, was forwarded to the DPZ for determination of the cause of death. The necropsy findings were hampered by autolysis of the carcass, but bacteriology revealed a septicaemia by Str. equi ssp. zooepidemicus (group C) as the cause of death. A similar case had been reported before only once, at the National Zoo, Washington D.C., USA, (another fatal infection of two mandrills within 3 days happened in 1997 at Hagenbecks Tierpark in Hamburg, Germany). The immediately initiated resistogram revealed the streptococci in Rheine to be susceptible to penicillin, and those in Hamburg to enrofloxacin. Immediate treatment with the respective antibiotics prevented further losses in both colonies. The source of infection in Rheine was most likely a volunteer suffering from a flu-like sore throat; in Hamburg it was a group of zebras in the direct neighborhood of the mandrills.

\subsection{Eikenella corrodens (Bacteroides c.) botryomycosis in a barbary ape (Macaca sylvana) from a safari park}

Botryomycosis is a Hoeppli phenomenon rarely observed in the skin of man and mostly caused by Staphylococcus aureus lysotypes II, III or V. In the 18-year-old female monkey presented here it was caused primarily by Eikenella corrodens, a microaerophilically growing Gram-negative $\mathrm{Bac}$ teroides species normally present in the oral cavity of man and animals. The monkey died from a botryomycosis-type pneumonia; it also suffered from a purulent mastitis caused by $S$. aureus lysotypes II/III/V, phagotypes 3A, C, 47, 54 and 94. Eikenella corrodens was isolated from the botryomycotic lung, and demonstrated histologically as Gramnegative bacterial colonies in the sublingual gland, sublingual lymph node and pancreas. S. aureus grew from the mamma and from a purulent sialoadenitis of the sublingual glands. The Hoeppli phenomenon was observed around the bacterial colonies in lung, lymph node and pancreas, but not in the inflamed mamma. Eikenella corrodens in the present case was resistant to most antibiotics, except ampicillin, penicillin, chloramphenicol and tetracycline (Brack, 1997).

\section{New World monkeys}

\subsection{Pachyonychia congenita in cotton-topped tamarins (Saguinus oedipus)}

In a $S$. oedipus colony acquired in 1978 from a virological institute in Germany, a total of 13 animals were observed to suffer from a spontaneous dermatosis, characterized by 


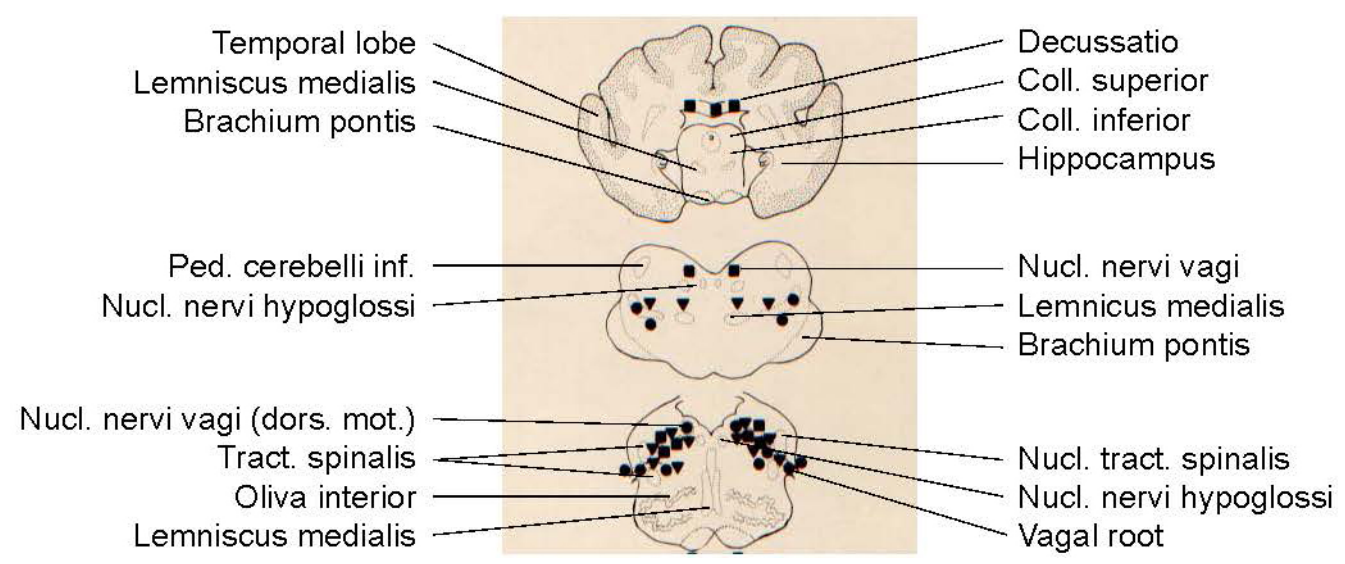

Figure 4. Distribution of herpetic lesions in the brains of newborn baboons following intratracheal SA8 infections.

alopecia totalis (except the long, white cranial hair), pigmentary disturbances and grotesquely elongated and twisted claws similar, but not identical, to human pachyonychia congenita. (Callitrichids possess nails only at their first digits; all other digits have claws, and only the claws were affected.) Pedigrees of the affected animals pointed to an autosomal recessive trait (Brack and Klensang, 1991). The neonatal death rate in certain affected families reached $100 \%$; the disease in surviving animals became obvious at approximately 6 months of age. Unfortunately subsequent follow-up genetic studies were not possible, since they would have required $5 \mathrm{~mL}$ blood from each animal weighing only approximately 100 to $300 \mathrm{~g}$. The colony was sold afterwards.

\subsection{Mesangial nephropathies in callitrichids}

One of the most frequent lesions seen at histopathology of captive marmosets and tamarins was alterations of the renal corpuscles. The lesions reached from mesangial hyperplasia beginning at the mesangial hilus, they extended peripherally to finally affecting the entire mesangial tree, leading to corpuscular obsolescence after contact of the glomerular tufts to the Bowman's capsule. Immunohistochemistry demonstrated the accumulation of mainly IgM complexes, sometimes also IgA complexes in the extended mesangia. Ultrastructurally the immunocomplexes appeared as electron-dense granules within the mesangial channels, accompanied by collagen IVfibers within the mesangial cytoplasm, both of which compressed the mesangial channels. A peculiar feature of only callitrichid mesangia has been the protrusion of the mesangial cellular matrix through endothelial fenestrations, considered to be signs of enhanced activity (Brack, 1983, 1990; Brack and Weber, 1995).

\subsection{Erysipelothrix insidiosa infections in callitrichids of a DPZ colony}

Erysipelothrix insidiosa, which normally causes erysipeloid in pigs and fatal infections in mice, was the cause of death in five marmosets dying from peracute myocarditis, hepatitis, intestinal haemorrhages and a mucoid enteritis especially of the duodenum and jejunum (Brack et al., 1999). The outbreak was stopped by vaccination of the entire population at risk, using a commercial porcine anti-E. insidiosa vaccine. Because the animals were kept behind barriers, the only epidemiology possibility seemed to be through a worker having contact to pigs at home.

\subsection{Isolation and identification of Brackiella oedipodis, gen. nov., sp. nov. at the DPZ}

A so-far-unknown new bacterium has been isolated at necropsy from the heart of a Saguinus oedipus dying from acute endocarditis. The new bacterium was characterized by $16 \mathrm{~S}$ rDNA sequence analysis, SDS-PAGE of whole-cell proteins, fatty-acid analysis, biochemical tests, outer membrane proteins and iron-regulated outer membrane proteins, lipopolysaccharides and siderophore production as a betaproteobacterium with a separate line of descent. Nearest phylogenetic neighbors are the genera Taylorella, Pelistega, Bordetella, Alcaligenes and Achromobacter. The name Brackiella oedipodis was proposed by the Robert Koch Institute, Berlin, Germany (Willems et al., 2002).

\subsection{Accidental poisoning of callitrichids at the University of Göttingen (Brack and Rothe, 1982)}

A long-standing breeding colony of Callithrix jacchus which was involved in a long-term breeding-behavioral project was virtually destroyed by the use of organophosphates for insect control instead of the required pyrethroids, thus violating the existing contract. A great number of the animals suffered from extreme behavioral disturbances, miosis or mydriasis 


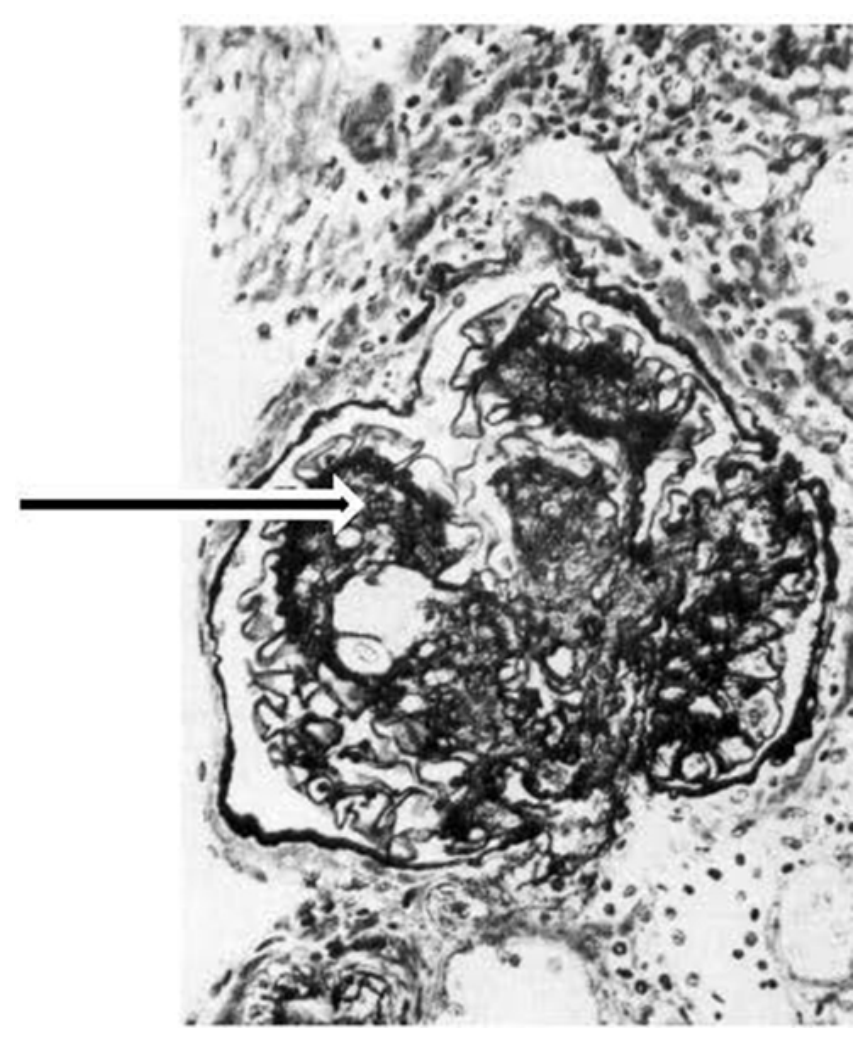

Figure 5. Advanced mesangial proliferation in callitrichid IgM nephropathy (arrow). Movat, 250×.

of the eyes, and in many, but not all, cases bloody-mucoid diarrhea. All alpha females of the colony died; the morphological lesions were non-specific, consisting of gastroenteritis and pharyngeal hyperemia. Curiously there were also certain destructions of plasticized building structures. The suspected poisoning was confirmed by the Institute of Forensic Medicine of the University of Göttingen as chlorpyrifos poisoning. Immediate treatment of the remaining animals by atropine sulfate and toxogonin saved most patients, but the loss of all alpha females made further behavioral studies in the colony futile.

\subsection{Angiostrongylus costaricensis in a black-eared marmoset (Callithrix penicillata) of the Magdeburg Zoo (Brack and Schröpel, 1995)}

A. costaricensis (Metastrongylidae) - whose primary hosts are neotropical cotton rats, rice rats and house rats - also infects man, particularly in Brazil. As a novum to Germany the parasite was found at necropsy of an adult female blackeared marmoset from the Magdeburg Zoo, Magdeburg, Germany, imported from Brazil 2 years before. The undernourished animal died suddenly without preceding clinical signs and was forwarded to the DPZ. The most prominent lesion at necropsy was a large granuloma at the ileocaecal angle, caused by infective rhabditiform helminthic larvae. The adult parasites, identified as A. costaricensis, inhabited a branch of the mesenteric artery and the portal vein, the larvae entered the intestinal lumen via the helminthic granuloma, thus possibly being fecally excreted. The main concern therefore was the protection of the environment at the Magdeburg Zoo and the prevention of introducing the parasite into Germany. Since the natural vectors are certain snails and slugs, a greater number of Limax species collected at the Magdeburg Zoo were examined, but no larval stages of metastrongylids were found.

\section{Tree shrews (Tupaia belangeri)}

\subsection{Pulmonary histiocytosis and adenocarcinomas in tree shrews (Brack et al., 1997c, 1966)}

Granulomatous lung lesions were registered in 65 tree shrews older than 3 months. They were present mostly around vascular structures primarily at the ventral margins of the lung lobes and resembled pulmonary histiocytosis of rats. The granulomas contained fibrous material without birefringence, as determined by both polarization and electron microscopy, but consisted of calcium according to energydispersive X-ray microanalysis. Faulty filtration in the ventilation system during the construction phase of the building was suspected to be the cause.

In 8 out of 524 tree shrews of unknown exposure to the calcium fibers, lung tumors developed: 4 bronchiolar tubular adenomas, 2 bronchial adenocarcinomas and 2 squamouscell carcinomas.

\subsection{Criokeron quintus (Cheyletidae) in tree shrews}

The rarely described exoparasite Criokeron (Nihelia) quintus caused subacute to chronic proliferative otitis externa and heavy pruritus in the tree shrews of the DPZ (Brack et al., 1989), a disease complex so far not described in Scandentia. Topically applied avermectins eradicated the parasites and stopped the auricular disease.

\subsection{Jugulo-sternal gland tumors (adenocarcinomas) in tree shrews}

Tree shrews like prosimians and certain euprimates possess a small, ill-defined cutaneous scent-marking gland at the lower ventral neck, consisting primarily of sebaceous gland tissues. In five adult males, that gland developed sebaceous adenocarcinomas; in one a papilliform adenoma of the apocrine tissues compartment was found instead. The adenocarcinomas tended to invade adjacent blood vessels; one had metastasized into the regional lymph nodes, thoracic muscles and the lungs (Brack, 1991). 


\subsection{Testicular tumors in tree shrews}

Testicular tumors are generally rare in nonhuman primates, including prosimians, but testicular alterations and finally tumors occurred frequently in the tree shrews of the DPZ. The testicular lesions in the tree shrews varied from stress-related hypospermatogenesis to testicular atrophy to testicular tumors. In total 1 hamartoma, 1 seminoma and 12 Leydig cell tumors were found, all preferring the left testicle and developing only in animals beyond 4 years of age (Brack, 1988; Brack and Fuchs, 2000).

\section{Monographs and book contributions}

To complete the scientific achievements of the Department of Pathology from 1973 to 1999 m the following publications should be mentioned:

- Brack, M.: Morphological and epidemiological aspects of simian herpesvirus infections, 1977.

- Brack, M.: Obligate and facultative pathogenic germs of primates, with supplement: classification of primates, 1980.

- Brack, M. and Niemitz, C.: The parasites of wild-caught tarsiers (Tarsius syrichta), 1984.

- Brack, M.: Agents transmissible from simians to man, 1987.

- Brack, M., Göltenboth, R., and Rietschel, W.: "Primaten", 1995.

That very abbreviated list of scientific activities does not contain the many publications on problems also reported by others, e.g., atherosclerosis and stroke in chimpanzees, mammary carcinomas in tree shrews, colonic signet-ring carcinomas in cotton-top tamarins, other tumors or parasitic or bacterial diseases already known to occur in nonhuman primates.

Not listed here are also the worldwide advice and assistance to zoological gardens, institutes or governments without publicity, but they have all contributed to the national and international reputation of the Department of Pathology and the DPZ in general.

Edited by: E. Fuchs

Reviewed by: F.-J. Kaup and one anonymous referee

\section{References}

Brack, M.: Perinatal Telencephalic Leucoencephalopathy in Chimpanzees, Acta Neuropathol., 25, 307-312, 1973.

Brack, M.: Morphological and epidemiological aspects of simian herpesvirus infections. Paul Parey Verlag, Hamburg-Berlin, 1977.
Brack, M.: Obligate and facultative pathogenic germs of primates, with supplement classification of primates, Publ. Soc. Lab. Anim. Sci., 8, 1-141, 1980.

Brack, M.: IgM-nephropathy in Callitrichids, Vet. Pathol., 25, 270276, 1983.

Brack, M.: Agents transmissible from simians to man, Springer, Heidelberg-Stuttgart, 1987.

Brack, M.: Malignant Leydig cell tumour in a Tupaia belangeri: case report and literature review of male genital tumours in nonhuman primates, Lab. Anim., 22, 131-134, 1988.

Brack, M.: IgM-Nephropathie (-Nephritis) bei Krallenaffen (Primates, Anthropoidea, Platyrrhini, Callitrichidae), J. Vet. Med. A, 37, 692-707, 1990.

Brack, M.: Jugulo-sternal gland tumors in male tree shrews (Tupaia belangeri), Lab. Anim. Sci., 41, 536-539, 1991.

Brack, M.: Eikenella corrodens - caused botryomycosis-type pneumonia in a Barbary ape (Macaca sylvana), Acta Pathol. Microbiol. Immunol. Scand., 105, 105, 457-462, 1997.

Brack, M. and Fuchs, E.: Incidence of testicular lesions in a population of tree shrews (Tupaia belangeri), Comp. Med., 50, 212 217, 2000.

Brack, M. and Gatesman, T. J.: Bilateral posterior parietal atrophy in an infant rhesus monkey (Macaca mulatta), J. Med. Primatol., 18, 43-54, 1989.

Brack, M. and Klensang, H.: Pachyonychia congenita-like disease in cotton-top tamarins (Saguinus oedipus oedipus), J. Med. Primatol., 20, 399-401, 1991.

Brack, M. and Rothe, H.: Organophosphate poisoning in marmosets, Lab. Anim., 16, 186-188, 1982.

Brack, M. and Schröpel, M.: Angiostrongylus costaricensis in a black-eared marmoset, Trop. Geogr. Med., 47, 136-138, 1995.

Brack, M. and Weber, M.: Ultrastructural and histochemical mesangial alterations in callitrichid mesangial nephropathy (Primates, Platyrrhini), Nephron, 69, 286-292, 1995.

Brack, M., Schwarz, P., Heinrichs, T., Schulz, M., and Fuchs, E.: Tumors of the respiratory tract observed at the German Primate Center 1978-1994, J. Med. Primatol., 25, 424-434, 1966.

Brack, M., Eichberg, J. W., Heberling, R. L., and Kalter, S. S.: Experimentelle Herpesvirus SA8-Encephalitis bei Kenia-Pavianen (Papio cynocephalus), Virchows Arch. A. Pathol. Anat., 392, 191-212, 1981a.

Brack, M., Eichberg, J. W., Heberling, R. L., and Kalter, S. S.: Experimentelle Herpesvirus SA8-Pneumonien (Bronchopneumonien) bei Kenia-Pavianen, Virchows Arch. A. Pathol. Anat. 392, 81-96, 1981b.

Brack, M. and Niemitz, C.: The parasites of wild-caught tarsiers (Tarsius syrichta), in: Biology of tarsiers, edited by: Niemitz, C., Gustav Fischer Verlag, Stuttgart-New York, 77-88, 1984.

Brack, M., Gatesman, T. J., and Fuchs, E.: Otacariasis in tree shrews (Tupaia belangeri) caused by Criokeron quintus, Lab. Anim. Sci., 39, 79-80, 1989.

Brack, M., Göltenboth, R., and Rietschel, W.: Primaten, in: Krankheiten der Zoo- und Wildtiere, edited by: Göltenboth, R., and Klös, H.-G., Blackwell Wissenschaftsverlag, 25-66, 1995.

Brack, M., Günther, E., Gilhaus, H., Salzert, W., and Meuthen, J.: An outbreak of Streptococcus equi ssp. zooepidemicus infection of probable human origin in wanderoos (Macaca silenus), Case report. Zbl. Bakteriol., 286, 441-446, 1997a. 
Brack, M., Hochleithner, C., Hochleithner, M., and Zenker, W.: Suspected dermatophilosis in an adult orangutan (Pongo pygmaeus pygmaeus), J. Zoo Wildl. Med., 28, 336-341, 1997b.

Brack, M., Schwarz, P., Fuchs, E., Heinrichs, T., and Dunckelberg, H.: Pulmonary histiocytosis in tree shrews (Tupaia belangeri), Lab. Anim. Sci., 47, 269-274, 1997c.

Brack, M., Tackmann, K., Conraths, F. J., and Rensing, S.: Alveolar hydatidosis (Echinococcus multilocularis) in a captive rhesus monkey (Macaca mulatta) in Germany, Trop. Med. Internat. Hlth., 2, 754-759, 1997d.

Brack, M., Rensing, S., and Gatesman, T. J.: Erysipelothrix insidiosa infection in callitrichidae behind a barrier system, Infect. Dis. Rev., 1, 15-19, 1999.
Dollinger, P., Brack, M., Furley, C. W., Moisson, P., Schoenbaum, M., Whitney, R. A., and Witt, C.-J.: Development of an international animal health codex recommendation for zoonoses transmissible from non-human primates, OIE, 1996, 19-22, 1996.

Willems, A., Gilhaus, H., Beer, W., Mietke, H., Gelderblom, R. A., Burghardt, B., Voigt, W., and Reisbrodt, R.: Brackiella oedipodis gen.nov., sp.nov., Gram-negative, oxidase-positive rods that cause endocarditis of cotton-topped tamarins (Saguinus oedipus), Internat. J. System. Evol. Microbiol., 52, 179-186, 2002. 